\title{
Напряженно-деформированное состояние горных пород северной части Ловозерского массива по данным изучения геологических индикаторов деформаций
}

\author{
Маринин А.В. ${ }^{1}$, Ловчиков А.В. ${ }^{2}$, Бондарь И.В. ${ }^{1}$ \\ ${ }^{1}$ Институт физики Земли им. О.Ю. Шмидта РАН, Москва, marinin@ifz.ru \\ ${ }^{2}$ Горный институт КНЦ РАН, Anamumbl, vocson@goi.kolasc.net.ru
}

Аннотация. Полевыми тектонофизическими методами получены данные о тектонических напряжениях северной части Ловозерского массива, ориентации осей главных напряжениях и типе напряженного состояния. Оси максимальных сжимающих напряжений ориентированы в северо-восточном и северо-западном направлениях, а единичные определения связаны с субширотной и субвертикальной ориентировкой оси максимального сжатия. Среди типов напряженного состояния преобладают обстановки горизонтального сжатия. Большинство разрывных нарушений, по всей видимости, используют первичную тектоническую делимость массива, связанную с субвертикальными тектоническими структурами северо-восточного и северо-западного простирания, а также с субгоризонтальными геологическими и тектоническими границами.

Ключевые слова. Балтийский щит, Кольский полуостров, Ловозерский массив, тектонические напряжения, тип напряженного состояния, структурные парагенезы, зеркала скольжения, разрывы, отрывы, трещины.

\section{Stress-and-strain reconstruction for the Northern segment of the Lovozero massif according to the study of geological stress indicators}

\author{
Marinin A.V. ${ }^{1}$, Lovchikov A.V. ${ }^{2}$, Bondar I.V. ${ }^{1}$ \\ ${ }^{1}$ The Schmidt Institute of Physics of the Earth of the RAS, Moscow,marinin@ifz.ru \\ ${ }^{2}$ Mining Institute of Kola scientific center of the RAS, Apatity, alovch@goi.kolasc.net.ru
}

\begin{abstract}
Reconstruction of tectonic stresses of the northern part of the Lovozero massif, the orientation of the principal stress axes and the stress regime were obtained by field tectonophysical methods. Axes of maximum compressive stresses oriented in the north-east and north-west directions and single definitions are associated with the sublatitudinal and subvertical orientation of the axis of maximum compression. Settings of horizontal compression dominate among the stress types. Most of the faults apparently have a primary tectonic divisibility of array associated with sub-vertical tectonic structures of the north-eastern and north-western strike, and also with sub-horizontal geological and tectonic boundaries.
\end{abstract}

Key words: Baltic Shield, Kola Peninsula, Lovozero Massif, tectonic stress, stress regime, tectonic pattern, slickensides, faults, tension gashes, joints.

Изучение тектонических напряжений в пределах Ловозерского и Хибинского массивов идет практически с начала их активного освоения и промышленной эксплуатации подземных горных выработок. Повышенные горизонтальные тектонические напряжения приводят к деформации подземных выработок, проявлению на них горных и горно-тектонических ударов (Ловчиков, 2008). В пределах Ловозерского массива действует рудник «Карнасурт», разрабатывающий Ловозерское месторождение редкоземельных металлов. В руднике ведётся подземная добыча лопаритовой руды в двух маломощных пластообразных рудных залежах, мощностью примерно по одному метру, пологопадающих под углом 10-15 ${ }^{\circ}$ в южных румбах и находящихся на расстоянии 90-120 м друг от друга по вертикали (Ловчиков, Савченко, 2013). Для Ловозерского массива до настоящего времени не применялись методы, ориентированные на изучение малых структурных форм (или геологических стресс-индикаторов) таких как зеркала скольжения, отрывы и т.д.

Для реконструкции напряженно-деформированного состояния с использованием полевых тектонофизических методов нами во время полевых исследований собраны структурнокинематические данные по геологическим индикаторам деформаций в северной части Ловозерского массива в пределах рудника «Карнасурт» и на естественных обнажениях, прилегающих к району 
расположения рудника. В 21 точке наблюдения в подземной части рудника и в 12 точках в поверхностной части сделано около 500 замеров (рис. 1). Из них 70 замеров со структурно-кинематической информацией, то есть с определением относительного направления перемещения крыльев мелких разрывных нарушений и зеркал скольжения.

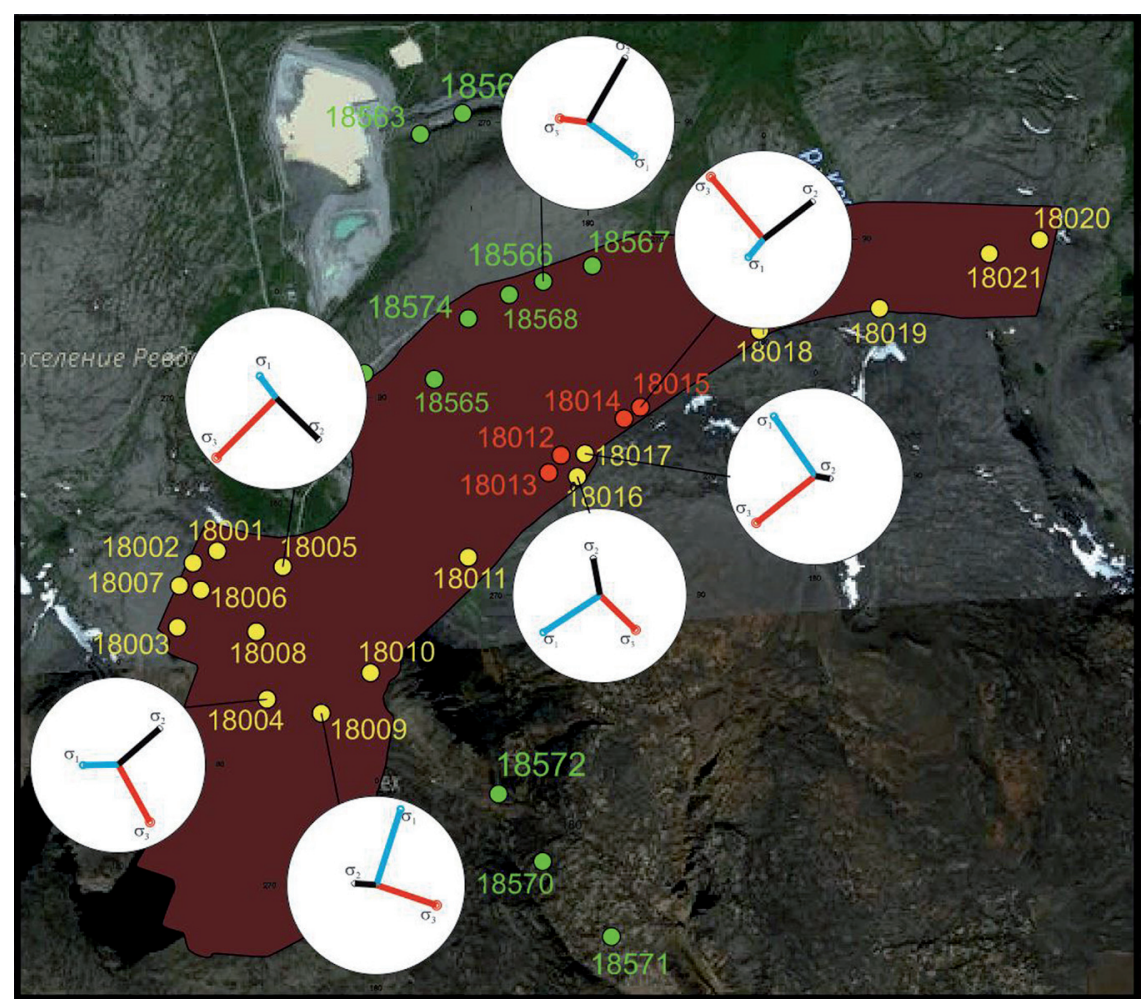

Рис. 1. Расположение точек наблюдения с контуром рудника (зеленым цветом - на поверхности, красным рудный горизонт I 4, желтым - рудный горизонт II 4) и ориентировка осей главных напряжений по данным проведенной реконструкции при помощи метода катакластического анализа геологических индикаторов напряжений (на диаграммах, стереографическая проекция на верхнюю полусферу): $\sigma_{1}$ - минимальных (растяжение, синий), $\sigma_{2}$ - промежуточных (черный) и $\sigma_{3}$ - максимальных (красный) сжимающих напряжений.

Fig. 1. The location of observation points with the mine contour (green - on the surface, red - ore horizon I 4, yellow - ore horizon II 4) and the orientation of the axes of the main stresses according to the reconstruction carried out using the method of cataclastic analysis of geological stress indicators (in diagrams, stereographic projection on the upper hemisphere): $\sigma_{1}$ - minimum (tension, blue), $\sigma_{2}$ - intermediate (black) and $\sigma_{3}$ - maximum (red) compressive stresses.

Для обработки замеров разрывных нарушений и зеркал скольжения с установленным характером смещений использовался метод катакластического анализа (Ребецкий, 2007) и созданная на его основе компьютерная программа STRESSgeol (Ребецкий, 2007; Ребецкий и др., 2017). Метод позволяет определить количественные характеристики реконструируемых локальных стресс-состояний, таких как положение осей главных напряжений, тип напряженного состояния, коэффициент ЛодеНадаи и др. Основные положения метода базируются на представлениях о квазипластическом деформировании геологической среды, установлении режима деформирования, положениях современной теории пластичности и максимуме диссипации внутренней упругой энергии для искомого тензора напряжений. Применяемая для расчетов программа STRESSgeol использует принцип разделения сколов на однородные выборки, определяющие временные фазы квазиоднородного деформирования макрообъема, для достижения максимальности суммарной энергии диссипации при минимальном количестве выделяемых фаз (Ребецкий, 2007; Ребецкий и др., 2017). В ряде точек собранных данных оказалась недостаточно для корректного расчета в программе STRESSgeol. Здесь было проведено сравнение с типовым структурными рисунками в рамках структурно-парагенетического метода Л.М. Расцветаева (1987). 
Для 7 точек наблюдения, расположенных в разных частях рудника (рис. 1), удалось реконструировать основные параметры локальных стресс-тензоров (ориентация осей главных напряжений, коэффициент Лоде-Надаи и др.). По этим данным составлена карта (рис. 1) и общая диаграмма погружений осей главных напряжений локальных стресс-состояний (рис. 2). По данным проведенной реконструкции в пределах изученной области преобладают обстановки горизонтального сжатия и сдвига (3 и 2 локальных стресс-состояний соответственно), но встречаются обстановки горизонтального растяжения и растяжения со сдвигом (2 локальных стресс-состояния). Интересно, что последние две обстановки зафиксированы на поверхности в т.н. 18566 или в подземной выработке т.н. 18016, но которая расположена недалеко от дневной поверхности и в непосредственной близости к долине реки.

Реконструированные оси максимальных сжимающих напряжений ориентированы в северовосточном и северо-западном направлении (рис. 2). Единичные определения связаны с субширотной и субвертикальной ориентировкой оси максимального сжатия. Оси промежуточных сжимающих напряжений имеют преимущественно северо-восточное направление (погружаются полого к юго-западу) или субвертикальны. Оси минимальных сжимающих напряжений в основном субвертикальные или ориентированы в направлении С3-ЮВ.
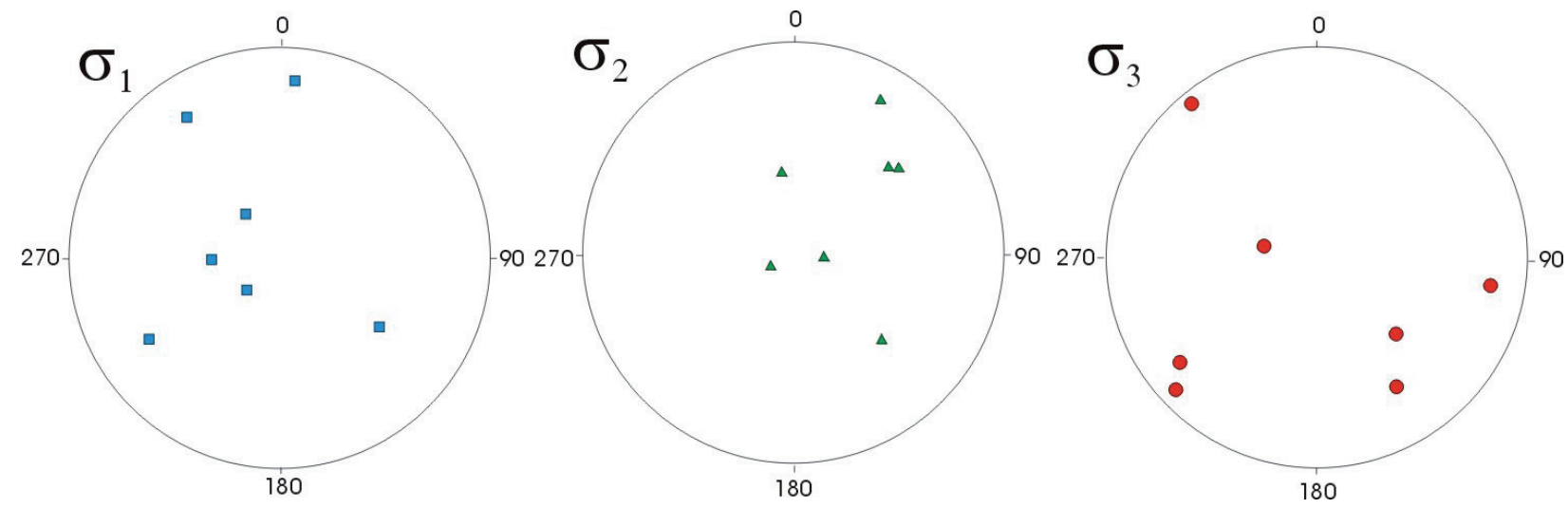

Рис. 2. Ориентировка осей главных напряжений по данным проведенной реконструкции при помощи метода катакластического анализа геологических индикаторов напряжений. На круговых диаграммах (стереографическая проекция на верхнюю полусферу) показано положение осей главных напряжений: $\sigma_{1}-$ минимальных (растяжение), $\sigma_{2}$ - промежуточных и $\sigma_{3}$ - максимальных (сжатие) сжимающих напряжений.

Fig. 2. Orientation of the principal stress axes according to the data of the reconstruction using the method of cataclastic analysis of geological stress indicators. Stereoplots (stereographic projection on the upper hemisphere) show the position of the principal stress axes: $\sigma_{1}-$ minimum (tension), $\sigma_{2}-$ intermediate and $\sigma_{3}-$ maximum (compression) compressive stresses.

Для точек наблюдения, где имелись замеры малых структурных форм, были построены диаграммы полюсов трещин для определения преобладающих направлений и кинематических типов. Для наиболее проявленного направления простирания (Ю3-СВ) дизъюнктивов фиксируются сбросовые, взбросовые и сдвиговые нарушения. В одних местах по этому направлению проявлены левые сдвиги, в других - правые. По такому же направлению фиксируются субвертикальные зоны дробления с неясной кинематикой. Сделанные определения в рамках структурно-парагенетического анализа по направлению максимального сжатия группируются следующим образом: с северо-восточным - 10 определений; с северо-западным (до СС3) - 4 определения; с субширотным - 3 определения. Для наиболее распространенных парагенезов с северо-восточной ориентировкой максимального сжатия характерна следующая кинематика мелких разрывных нарушений (зеркал скольжения): субмеридионального и ССВ простирания правые сдвиги (т.н. 18001, 18009, 18566), субширотного простирания левые сдвиги (т.н. 18005, 18017, 18020, 18573), взбросо-надвиговые структуры с северовосточным (до ВСВ) падением плоскости сместителя (т.н. 18005, 18013). 
По исследованной области также построены диаграммы тектонической трещиноватости (без видимых следов смещений), которые показали наличие трех основных систем, две из которых преимущественно субвертикальные с С3 и СВ простиранием, а третья пологая субгоризонтальная система. В некоторых местах преобладает одна из вышеописанных систем. В других случаях проявлена субширотная система с достаточно крутым падением.

Таким образом, по данным полевых тектонофизических исследований оси максимальных сжимающих напряжений ориентированы преимущественно в северо-восточном и северо-западном направлениях. Единичные определения связаны с широтной и вертикальной ориентировкой оси максимального сжатия. По типу напряженного состояния в северной части Ловозерского массива преобладают обстановки горизонтального сжатия. Большинство малых структурных форм и небольших разрывных нарушений, по всей видимости, используют первичную делимость массива, которая в свою очередь связана с субвертикальными тектоническими структурами северо-восточного и северо-западного простирания, а также с субгоризонтальными геологическими и тектоническими границами.

Исследования поддержаны грантами РФФИ 17-05-01193 и 18-05-00563.

\section{Литература}

1. Ловчиков А.В. Савченко С.Н. Напряженное состояние горных пород вблизи очистных выработок на руднике «Карнасурт» // Вестник МГТУ. 2013. Т. 16. № 4. С. 741-747.

2. Ловчиков А.В. Горно-тектонические удары на Ловозерском редкометальном месторождении // Вестник МГТУ. Т. 11. № 3. 2008. С. 385-392.

3. Расцветаев Л.М. Парагенетический метод структурного анализа дизъюнктивных тектонических нарушений. Проблемы структурной геологии и физики тектонических процессов. М.: ГИН АН СССР. 1987. Ч. 2. C. $173-235$.

4. Ребецкий Ю.Л. Тектонические напряжения и прочность горных массивов. М. Издво: Наука. 2007. 406 с.

5. Ребецкий Ю.Л., Сим Л.А., Маринин А.В. От зеркал скольжения к тектоническим напряжениям. Методы и алгоритмы / Ю.Л. Ребецкий, Л.А. Сим, А.В. Маринин; отв. редактор Ю.Г. Леонов; Институт физики Земли им. О.Ю. Шмидта РАН. М. Изд-во: ГЕОС. 2017. 225 с. 